\title{
The application of an Auto-stereoscopic Display in Design and Construction
}

\author{
Naai-Jung Shih \\ National Taiwan University of Science and Technology, Department of Architecture, \\ 43, Section 4, Keelung road, Taipei, Taiwan, ROC. \\ shihnj@mail.ntust.edu.tw
}

\begin{abstract}
This study explores the application patterns of an auto-stereoscopic display (ASD) in architecture. An ASD set-up is exemplified to serve computer supported collaborative works (CSCW) and construction needs. The system is applied to both geometry- and image-based VR contents. A DTi 18.1" ASD is used for content illustration of still images and videos.
\end{abstract}

KEYWORDS: auto-stereoscopic display (ASD), 3D display, VR

\section{INTRODUCTION}

Architecture-related application of autostereoscopic display (ASD) is still limited. Most of the application are presented through a stereoscopic view of virtual data with an HMD. In reality, activities usually occur when no 3D modeling data are available. The recording and post-representation of the situation is a complicated task. The application of stereoscopic display can be seen in the reconstruction of crime scenes (Howard 2000), Internet video transmission (Johnson 2001), 3D TV (Karwowska-Lamparska 2000), size (Kobayashi 1999), crane operations (Quek et al. 2000), and mechanical engineering (Tuokko 1999). Autostereoscopic display application can be seen in medical treatment planning (Christopher et al. 1999), volume rendering (Hubbold 1998), undersea imaging and measurement systems (Liu 2001), and 3D data viewing on the Internet (Uchiyama, 1998). The involvement of multiple observers is also feasible with these applications (Kitamura 2001). However, the capability of currently available computer systems may not be enough to deliver a truly 3D scene remotely. The influence of display devices on architectural data types and sources also remains to be studied.

\section{RESEARCH PURPOSE}

This study explores the application patterns of an ASD in architecture. An ASD setup is exemplified to serve computer supported collaborative works $(\mathrm{CSCW})$ and construction needs.

\section{VR TECHNOLOGY}

3D display contents usually come from different types of sources that correspond to the outcome of the $3 \mathrm{D}$ modeling programs. To transfer a 3D scene to a VR format not only involves taking into consideration of the characteristics of the 3D data, but also preparing an appropriate display system for the data. Although the types of interaction can be categorized into VR, augmented reality, diminished reality, and mediated reality based on Steve Mann's classifications, this paper emphasizes the common VR definition, which includes geometry- and image-based VR.

\section{1 VR types}

VR can be categorized into geometry-based and image-based types.

- geometry-based VR: This type directly transfers 3D geometries created in application programs to formats suitable for VR interface or interaction. Most of the geometric characteristics are kept and can be manipulated in 360 degrees by a mouse. A user can walk-through or fly-through a scene.

- image-based VR: This VR type applies images to simulate views of an object or a scene from different angles, as if the viewed is located at the center. Images can be stitched into panoramas or to objects for an off-center or toward-center inspection. No geometric object has to be created beforehand. Imagebased VR usually provides better visual details because the pictures are of photograph quality. 


\subsection{Types of 3D VR display systems}

Stereoscopic, autostereoscopic, and volumetric display are three types of illustration that can offer users a 3D sense of objects.

- Stereoscopic:

- Anaglyph method: This method uses color or polarized lens to differentiate the images for the left and right eye.

- Frame-sequential method: This method uses LCD shutter glasses to differentiate the display sequence of images for the left and the right eye.

- Autostereoscopic: This is similar to stereoscopic display, but no glasses are needed. An ordinary VR interface tracks the viewer's orientation in order to display the corresponding contents from a computer. The track holder also determines what other viewers see. In group communication, the control of the viewport has to be passed around if anyone else wants to show his or her view. However, this type of content delivery does not necessarily meet the individual needs of interaction in group communication.

- Volumetric: This applies solid volume, multiplanar, or electro-holographic display to increase the depth of an image

This autostereoscopic display use of technology in architecture can be seen in multi-planar, parallax barrier, or directional projection. Currently used ASD methods are listed as follows.

- DTi display (see Fig. 1): This was a lenticular screen to differentiate the images for both eyes. A user can perceive an optical depth of space when the eyes are properly positioned.

- Synthgram display (see Fig. 1): The display screen is divided into nine regions for corresponding viewing orientations of an object. A user can perceive depth of space in more directions with fewer blind spots.
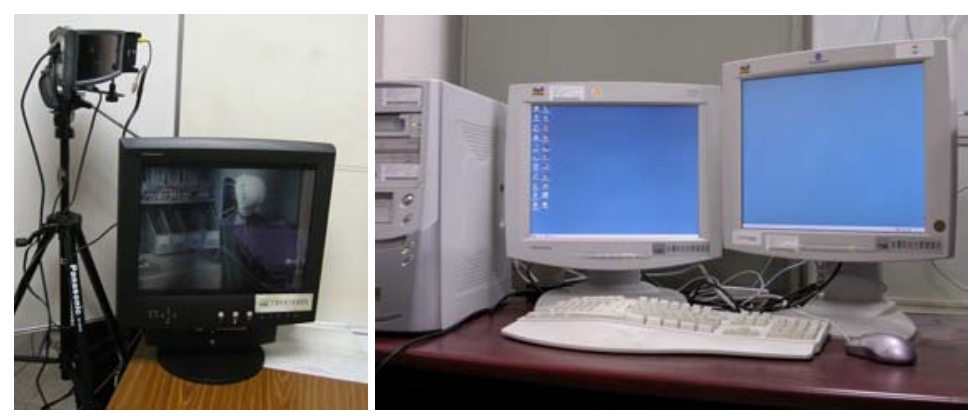

Figure 1. DTi display, camcorder, and stereo lens (left); Synthagram display (right)

Table 1. List of autostereoscopic display contents

\begin{tabular}{|c|c|c|c|c|c|c|}
\hline & targets & $\begin{array}{l}\text { hardware (retrieval } \\
\text { devices) }\end{array}$ & Sources of data & $\begin{array}{l}\text { Image } \\
\text { types }\end{array}$ & $\begin{array}{l}\text { content } \\
\text { creation } \\
\text { software }\end{array}$ & $\begin{array}{l}\text { Auto-stereo- } \\
\text { scopic } \\
\text { interface }\end{array}$ \\
\hline VR still & $\begin{array}{l}\text { image } \\
\mathrm{s}\end{array}$ & $\begin{array}{l}\text { Pair software } \\
\text { camera shots }\end{array}$ & $\begin{array}{l}\text { still computer } \\
\text { image pairs }\end{array}$ & fixed views & $\begin{array}{l}\text { any 3D } \\
\text { renderer }\end{array}$ & DTi \\
\hline $\begin{array}{l}\text { VR } \\
\text { panoram } \\
\text { a still }\end{array}$ & $\begin{array}{l}\text { image } \\
\mathrm{s}\end{array}$ & $\begin{array}{l}\text { Panorama } \\
\text { renderer } \\
\text { Camera shot } \\
\text { stitches }\end{array}$ & $\begin{array}{l}\text { Dewarped } \\
\text { panoramas } \\
\text { still computer } \\
\text { image sequence }\end{array}$ & $\begin{array}{l}\text { panorama } \\
\mathrm{s}\end{array}$ & $\begin{array}{l}\text { ArchiCAD } \\
\text { ArtRentis } \\
\text { 3D Studio }\end{array}$ & DTi \\
\hline $\begin{array}{l}\text { VR } \\
\text { panoram } \\
\text { a video }\end{array}$ & videos & $\begin{array}{l}\text { Panorama } \\
\text { renderer } \\
\text { Camera shot } \\
\text { stitches }\end{array}$ & panorama video & $\begin{array}{l}\text { Panorama } \\
\text { views }\end{array}$ & $\begin{array}{l}\text { Panorama } \\
\text { Maker } 3.0\end{array}$ & DTi \\
\hline RW still & $\begin{array}{l}\text { objects } \\
\text { image } \\
\mathrm{s}\end{array}$ & Pair camera shots & still image pairs & fixed views & & DTi \\
\hline $\begin{array}{l}\mathrm{RW} \\
\text { video }\end{array}$ & objects & $\begin{array}{l}\text { DV camcorder with } \\
\text { Nu-View stereo } \\
\text { lens }\end{array}$ & $\begin{array}{l}\text { parallax analog } \\
\text { video signal }\end{array}$ & fixed views & & DTi \\
\hline $\begin{array}{l}\mathrm{RW} \\
\text { panoram } \\
\text { a video }\end{array}$ & objects & $\begin{array}{l}\text { Paradome } \\
\text { Panashot lens } \\
\text { attachment and } \\
\text { netcam } \\
\text { NetVIsion } 360\end{array}$ & $\begin{array}{l}\text { parallax analog } \\
\text { video signal }\end{array}$ & $\begin{array}{l}\text { Panorama } \\
\text { views }\end{array}$ & $\begin{array}{l}\text { Paradome } \\
\text { Panashot }\end{array}$ & DTi \\
\hline
\end{tabular}




\section{VR AND REAL WORLD DISPLAY OF OBJECTS AND SCENES}

VR format and ASD need to be incorporated into the architectural modeling process for the easy setup of an application environment. Both geometry-based and image-based VR types can now be used in an ASD mode (see Tab. 1). Geometry-based VR requires the use of a specially designed lens to separate the views for each eye. Views can be recorded as a single image pair or as a mixed video signal. The lens can be pointed toward the orientation as generated to generate a panorama-like experience. Similar to image-based VR, pictures are taken at a distance that is about equivalent to the length between the eyes (8 inches in general) (see Fig. 2 \& 3). Adjustment has to be made to paired panoramas to generate an autostereoscopic view from all angles. The ASD and a lens can be connected by cables or through the Internet. A wireless connection is also possible using a $2.4 \mathrm{GHz} \mathrm{AV}$ sender and receiver.

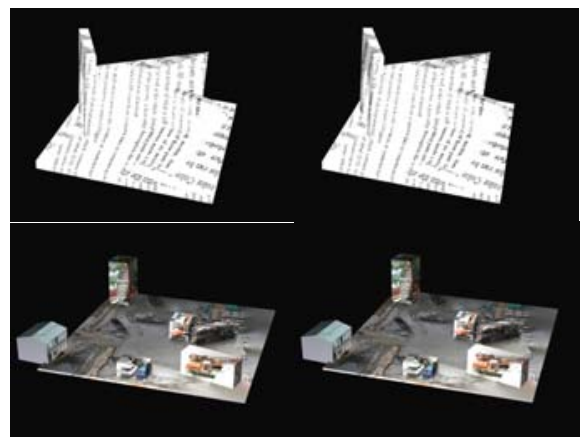

Figure .2 Image for auto-stereographic display

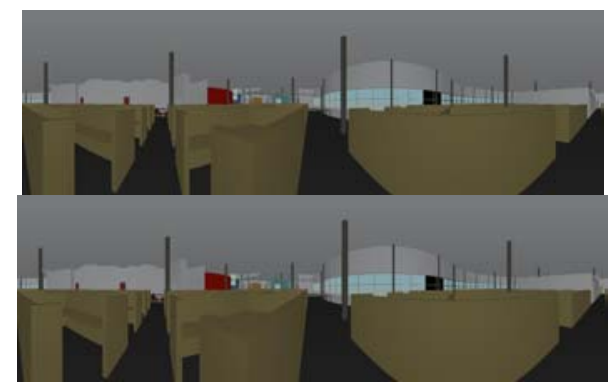

Figure 3. Image for auto-stereographic panorama display

\subsection{The advantages of an autostereoscopic systems}

In addition to aiding design evaluation and data visualization, an autostereoscopic system has the following advantages.

- No HMD or shutter glass is needed. Some of the display provides real-time $3 \mathrm{D}$ views. A variety of formats (video stream or .X,
VRML, etc. files) can be supported.

- A much lower installation cost is required than with a CAVE setup.

- The possibility of fatigue is reduced as no glasses are needed.

\section{CSCW}

Design communication can involve both individuals and teams. One of the factors that affect the efficiency of communication is the quality of media used to represent the design contents. Media varies from photos and digital images, to computer models that are captured or created under different circumstances and stages of design. Before the construction of a design, the communication relies heavily on digital data that can serve different levels of viewing needs in the form of animation or stereographic display.

The situation changes when the CSCW contents come from a site that may not exist in finished digital form. In this case, the data must be delivered in a comprehensive manner with a simple setup of devices. This is where an ASD is involved (see Fig. 4). Since design communication usually involves multiple expertise, an HMD type of display is unlikely to be applied without obstruction.

One of the purposes of $\mathrm{CSCW}$ is to clarify the ambiguities than can occur in the design process that allows response with the assistance of visualization tools. Formal studies emphasize analysis based on communication model made up of sender, channel, receiver, and feedback. When VR technology is applied during the construction stage, a user can interact with the data more intuitively.

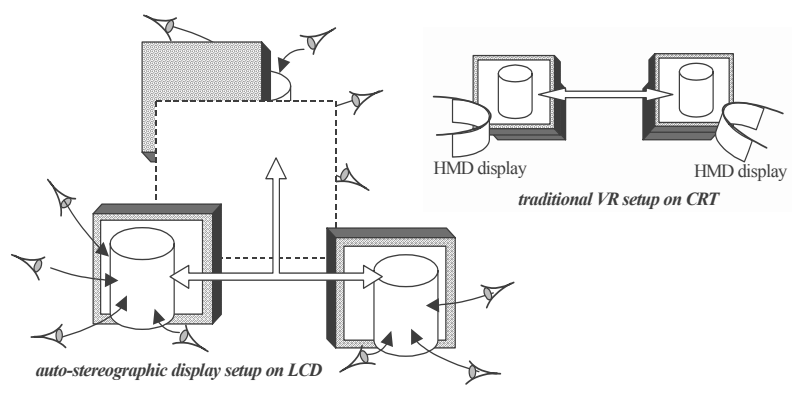

Figure 4. Comparison between traditional VR interface and ASD systems

To communicate about a physically presented object, the device setup for CSCW includes a stereo lens attached to a camcorder (see Fig. 5). The wireless video signal is transmitted to a server 
with a receiver attached to a capture card at the back. The video is then viewed through the Internet. The camcorder and stereo lens, which act as a webcam, can be moved around as long as they are within the range of perception and a battery is provided as the AV sender's power supply. For an ASD, the viewer side needs a corresponding monitor that is ready and switched to autostereoscopic mode. Design work shown from different display method (Synthagram) can also be seen in Fig. 6.

In order to conduct $\mathrm{CSCW}$ in $\mathrm{ASD}$, the data of real or virtual subjects feature differently for synchronized or unsynchronized communication. A graphic database has to be categorized accordingly. As shown in Tab. 1, the ASD contents vary as physically presented objects are replaced by computer models. In the meantime, paired images have to be rendered before being posted on web pages. A static ASD effect is made by downloading the images and composing them afterward using the display program provided. For Synthagram, ASD is made by executing a plug-in in 3D Studio for previously created models. An ASD environment is exclusively used for a virtual world. Nevertheless, a closer connection is made with an already familiar modeling process.

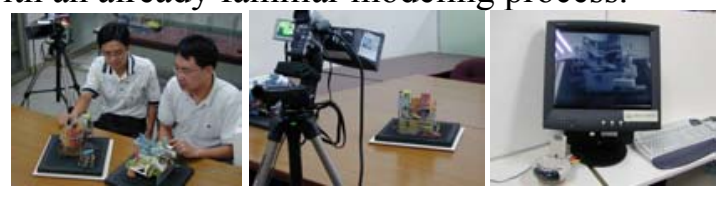

Figure 5. CSCW through an ASD using $2.4 \mathrm{GHz}$ wireless $A / V$ sender/receiver
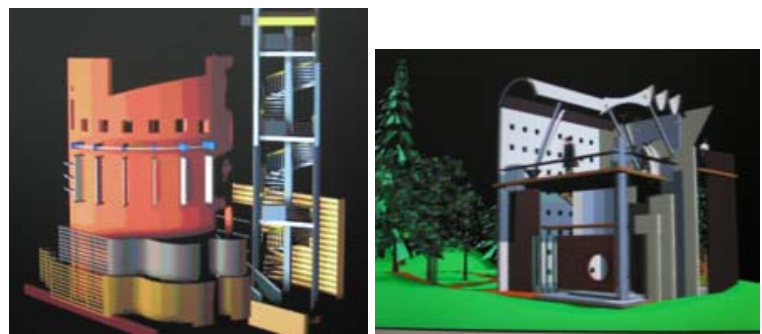

Figure 6. Design work shown from Synthagram display

Panoramic display in auto-stereoscopic form gives the people on the receiving end an immersive feeling that actually helps to shorten the virtual distance or between sender and receiver. The receiver is aware of the responses of the other parties involved (such as other students or instructors) instead of the responses only of designers and presenters. Whether a panoramic display should be provided for unsynchronized communication remains to be seen. The panoramic view really helps in showing a remote site, especially in an immersive manner.

A test was made to create paired panoramas for auto-stereoscopic display. But the effective region was limited to a fixed orientation. To mimic the eyes' eccentric viewing of a 360-degree space, paired cameras have to be allocated in the same manner. For a currently available panorama device that is made up of a number of eccentric lenses, the images captured from auto-stereoscopic panorama cameras have to be selected at every other one before being stitched together. This is different from placing a pair of panorama lens attachments and combining two of them side by side.

\section{CONSTRUCTION}

ASD was used at a construction site (see Fig. 7) with a wireless connection. The distance between sender and receiver was about 50 meters with the former located at the bottom of an excavated third basement floor and the other on the eighth floor of a building nearby. The device setup was rather simple. Signals were transmitted barrier-free while the line of sight was also maintained unblocked for best results. The display clearly showed the steel columns and beams that support retaining walls with visual depth.

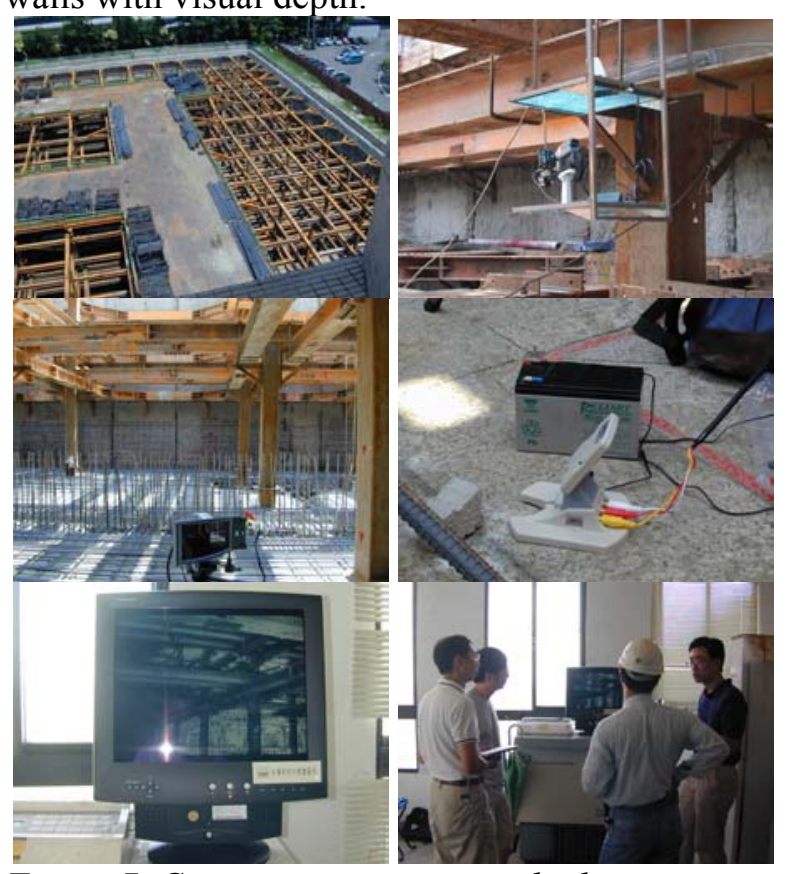

Figure 7. Construction site as applied

Discussion with the project manager showed that the setup was most suitable for a site with potential hazards, as no persons need to be 
present, for example at a tunnel excavation. For a site of about $75 \times 72$ meters in size and with offices located nearby, works can respond to any site occurrence immediately. The display seems to them less important compared to that of traditional camcorder, unless communication has to be made to the client for a presentation that is more comprehensive.

A construction site is full of complicated activities. Many systems are involved to assist the representation, control, or monitoring of a site with devices such as camcorders, PDAs, or GPSs. The combination of these enables a supervisor to view what is happening at an exact location with immediate video delivery. Now, a GPS can increase the accuracy to about 1 meter. PHS also helps to locate the location of signals. With wide band or high frequency $(2.4 \mathrm{GHz})$ available, immediate video streaming becomes available and accessible all over the site.

The current market only offers a desktop ASD of 15 " or 18.1". An HMD-free display is better placed in an interior with a power supply. The price of an 18.1" HMD-free ASD can reach USD7000. A portable CRT with HMD could be a set of compact displays installed in large quantities to view 3D scenes at a distance from other locations. However, the small size of the screen may prevent it from providing a clear display. Plan for installing an ASD on a tower crane are currently underway. Controlling the lifting or placing of objects with the crane should be more certain with the resulting enhancement of visual depth.

\section{APPLICATION PATTERNS AND EXEMPLIFICATION}

ASD application in architecture can be seen in many different subjects and fields.

- Visualization of physically presented objects or scenes: in urban and other environments

- Visualization of virtual objects or scenes

- historical architectural objects: Chinese architecture

- architectural design

- hazard prevention

- building construction: machine operation

- Process inspection

- tele-operation and autonomous robots for construction

- control systems for construction machinery (cranes, bulldozers, excavators, etc.)
- computer-integrated building process studies

- construction process modeling and simulation

- monitoring and control of construction processes

- construction work process modeling and automation

\section{CONCLUSION}

The application of ASD in architectural studies leads to an immersive communication in a small region of display. A corresponding device setup is rather simple, maintenance-free, and low in cost compared to a CAVE-like environment. All components are available on the market. The major task in supporting a study would be the preparation of graphic data for corresponding subjects in a virtual world via renderings or a real world via pictures or videos. 


\section{REFERENCES}

Christopher M, Roger H, David H. (1999). 3D sculpting and auto-stereoscopic display of ICRU-50 volumes and anatomy in conformal radiotherapy treatment planning. Proceedings of the First Joint BMES/EMBS Conference. 1999 IEEE Engineering in Medicine and Biology 21st Annual Conference and the 1999 Annual Fall Meeting of the Biomedical Engineering Society. IEEE. Part vol.2, 1999, pp.1165 vol.2. Piscataway, NJ, USA.

Howard TLJ, Murta AD, Gibson S. (2000). Virtual environments for scene of crime reconstruction and analysis. SPIE-Int. Soc. Opt. Eng. Proceedings of Spie - the International Society for Optical Engineering, vol.3960, pp.41-8. USA.

Hubbold RJ, Hancock DJ, Moore CJ. (1998). Stereoscopic volume rendering. Visualization in Scientific Computing '98. Proceedings of the Eurographics Workshop. Springer-Verlag, pp.105-49. Wien, Austria.

Johanson M. (2001). Stereoscopic video transmission over the Internet. Proceedings. The Second IEEE Workshop on Internet Applications. WIAPP 2001. IEEE Comput. Soc., pp.12-19. Los Alamitos, CA, USA.

Karwowska-Lamparska A. (2000). Three dimensional TV (3D). Przeglad Telekomunikacyjny + Wiadomosci Telekomunicayjne, vol.73, no.1, pp.69-74. Publisher: SIGMA NOT, Poland.

Kitamura Y, Konishi T, Masaki T, Kishino F. (2001). IllusionHole: a stereoscopic display for multiple observers. SPIE-Int. Soc. Opt. Eng. Proceedings of Spie - the International Society for Optical Engineering, vol.4297, pp.360-8. USA.

Kobayashi M, Shiwa S, Kitagawa A, Shimada Y, Ichinose S. (1999). Sharing impression of size: stereoscopic approach for real scale video. Transactions of the Information Processing Society of Japan, vol.40, no.11, Nov. pp.3834-46. Publisher: Inf. Process. Soc. Japan, Japan.

Liu HT. (2001). A video-based stereoscopic imaging and measurement system (SIMS) for undersea applications. MTS/IEEE Oceans 2001. An Ocean Odyssey. Conference Proceedings (IEEE Cat. No.01CH37295). Marine Technol. Soc. Part vol.1, pp.275-86 vol.1. Washington, DC, USA.

Quek RSM, Lim KY, Pang TK, Chui YP. (2000). An assessment of container handling performance using a two- and threedimensional remote crane display. Proceedings of the Joint Conference of APCHI 2000 (4th Asia Pacific Conference on Human Computer Interaction). ASEAN Ergonomics 2000 (6th S.E. Asian Ergonomics Society Conference). Elsevier Science, pp.57-61. Kidlington, UK.

Tuokko R. (1999). Virtual reality-a key technology in development of Finnish mechanical engineering and automation industry. IMEKO - XV. World Congress. Measurement to Improve the Quality of Life in the 21st Century - Measurement Helps to Coordinate Nature with Human Activities Vol. X. TEG-17. ISMCR'99 Topical Workshop on Virtual Reality and Advanced Human-Robot Systems. IMEKO, pp.28390. Budapest, Hungary.

Uchiyama S, Yamamoto H, Tamura H. (1998). An auto-stereoscopic VRML viewer for $3 D$ data on the World Wide Web. VSMM98. 4th International Conference on Virtual Systems and Multimedia. Futurefusion. Application Realities for the Virtual Age. Proceedings. IOS Press \& Ohmsha. Part vol.2, pp.566-71 vol.2. Amsterdam, Netherlands \& Tokyo, Japan. 